\title{
Research on Real-Time Monitoring of Strain Behavior of Concrete under Freezing-Thawing Cycle by White Light Interferometer
}

\author{
Haifeng Lv, ${ }^{1}$ Xianglong Kong, ${ }^{2}$ Jie Ren, ${ }^{3}$ Xuefeng Zhao ${ }^{(D)},{ }^{4}$ and Changsen Sun ${ }^{5}$ \\ ${ }^{1}$ Shandong Provincial Key Laboratory of Civil Engineering Disaster Prevention and Mitigation, \\ Shandong University of Science and Technology, Qingdao 266590, China \\ ${ }^{2}$ Suzhou Nuclear Power Research Institute, Suzhou 215004, China \\ ${ }^{3}$ Construction Project Quality Safety Technology Service Center, \\ Ordos Municipal Bureau of Housing and Urban-Rural of Development, Ordos 017010, China \\ ${ }^{4}$ School of Civil Engineering, State Key Laboratory of Coastal and Offshore Engineering, Dalian University of Technology, \\ Dalian 116024, China \\ ${ }^{5}$ College of Physics and Optoelectronic Engineering, Dalian University of Technology, Dalian 116024, China
}

Correspondence should be addressed to Xuefeng Zhao; zhaoxf@dlut.edu.cn

Received 16 November 2021; Accepted 13 January 2022; Published 25 January 2022

Academic Editor: Zhengyang Song

Copyright ( $\odot 2022$ Haifeng Lv et al. This is an open access article distributed under the Creative Commons Attribution License, which permits unrestricted use, distribution, and reproduction in any medium, provided the original work is properly cited.

\begin{abstract}
To study the degenerative process of concrete subjected to freezing-thawing (F-T) cycles in real-time, the strain behavior of concrete cylinder was monitored by a fiber optic F-T testing method based on the white light interferometer (WLI) technique. The principle of the WLI technique was described in detail and the design of the fiber optic testing method. Two mixed proportions of concrete immersed in $3.5 \% \mathrm{NaCl}$ solution were tested in a freeze-thaw testing machine. The theory and method of temperature compensation were stated in detail. The results indicated that the variation of strain decreases in the cooling stage and increases in the heating stage in a F-T cycle. The residual strain was generated in the test.
\end{abstract}

\section{Introduction}

In cold regions, F-T cycling is one of the main reasons for degradation of concrete materials because of the pore water. The change of dimensional and internal stress will be caused during the F-T cycles, which can result in degeneration and failure of concrete structures $[1,2]$.

Nowadays, the loss of weight and relative dynamic modulus of elasticity are the most popularly used to evaluate the $\mathrm{F}-\mathrm{T}$ resistance of concrete [3-5]. Other indicators are also used to evaluate the degradation of concrete subjected to F-T cycles, such as dimensional change [6] and strength $[7,8]$. However, these indicators differ in the testing methods and evaluation criteria. In addition, the workload is hefty, and the artificial factor has a significant effect on the results. With the development of technology, many image processing techniques have been used to study material damage, such as the digital image processing (DIP) technique $[9,10]$, X-ray computed tomography [11], high speedcamera [12], ultrasonic imaging [13], scanning electron microscopy (SEM) [14], and magnetic resonance imaging $[15,16]$. Besides, the nondestructive testing methods are also introduced to assess degeneration of materials, which are the fundamental transverse frequencies [17] and acoustic emission $[18,19]$. However, none of these methods could achieve real-time monitoring the damage evolution of concrete during freezing-thawing cycles.

Study of the degenerative process of concrete in realtime during F-T cycles is very important, which could make the degenerative process intuitive and make it possible to give an alarm value according to the degenerative process in time. In order to study the degeneration of concrete in real- 
time during the process of F-T cycles, some researchers have studied it in different technical methods and analytical perspectives. Ranz [20] and Cao [21] studied the degeneration of concrete during the F-T cycles with ultrasonic transducers and electrical resistivity measurement methods. Bishnoi [22] embedded the strain gauges in concrete to measure the inner strain, and the results demonstrated that the inner strain increases with the progress of deterioration.

Under the action of a freezing-thawing cycle, microcracks will occur inside the material, which will inevitably lead to volume change $[23,24]$. The strain of concrete will occur during the process of F-T cycles, which is a very important feedback signal, and it could give a holistic perspective to study the inner damage of concrete and make it possible to quantify the damage of concrete.

In this study, based on the WLI technology, a real-time monitoring method was proposed, and the strain behavior of concrete cylinder was monitored during the F-T cycles. Concrete specimens with 0.55 and 0.35 water-cement ratios (W/C), which were immersed in $3.5 \% \mathrm{NaCl}$ solution, were tested in a temperature chamber to simulate the F-T environment and chloride salt attack. The theory and method of temperature compensation were stated in detail, and the strain behavior of T-specimen was monitored and studied during the F-T cycles. Besides, the mechanism of F-T degeneration was also analyzed from the perspective of strain.

\section{The Principal of WLI}

A diagram of the WLI sensing technique is shown in Figure 1. The system comprises a superluminescent emitting diode (SLED), a $3 \mathrm{~dB}$ fiber optic coupler, which is used to separate and recombine the light, a photoelectric detector (PD), which is used to detect the white light interference fingers, reference fiber, and sensing fiber. The light emitted from the SLED is divided into two beams after passing the fiber optic coupler when the system is working and going into the reference fiber and sensing fiber, respectively. One beam light arrives at the PD after going through the reference fiber and being reflected by the reflector. The other beam light also arrives at the PD after going through the sensing fiber and being reflected by a scanning mirror. When the optical paths of the two beams are equal, white light interference fringes will be shown in the PD, as shown in Figure 2, where the position $\left(X_{0}\right)$ will be recorded as a calibrated position. This procedure can be repeated for locating the new fringe $\left(X_{1}\right)$ when the length of the sensing fiber $\left(l_{0}\right)$ changes. Therefore, the length of the reference fiber will be recalculated by confirming the position of the scanning mirror, and the change of length for the sensing fiber will be obtained. The following equation can be established [25]:

$$
\begin{aligned}
\Delta l & =\left|X_{1}-X_{0}\right| \bullet \frac{L_{N}}{n}, \\
\varepsilon & =\frac{\Delta l}{l_{0}},
\end{aligned}
$$

where $\varepsilon$ is the strain, $L_{N}$ is $1.25 \mu \mathrm{m}, n$ is the effective refractive index of the sensing fiber, $\Delta l$ is the absolute deformation, and $l_{0}$ is the length of the sensing arm.

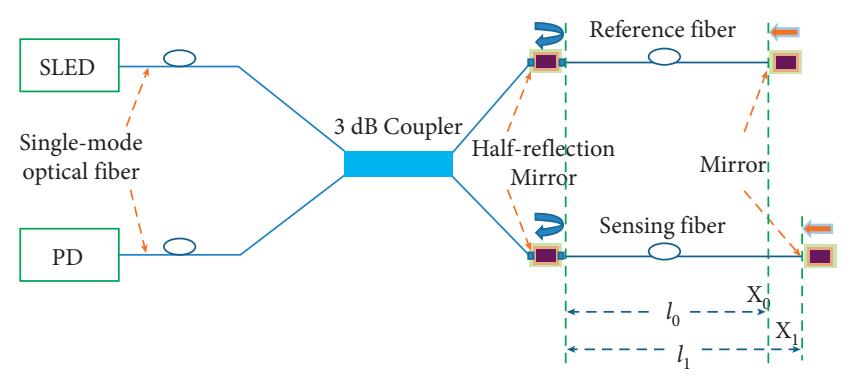

FIgURE 1: Typical experimental setup of the WLI sensing technique.

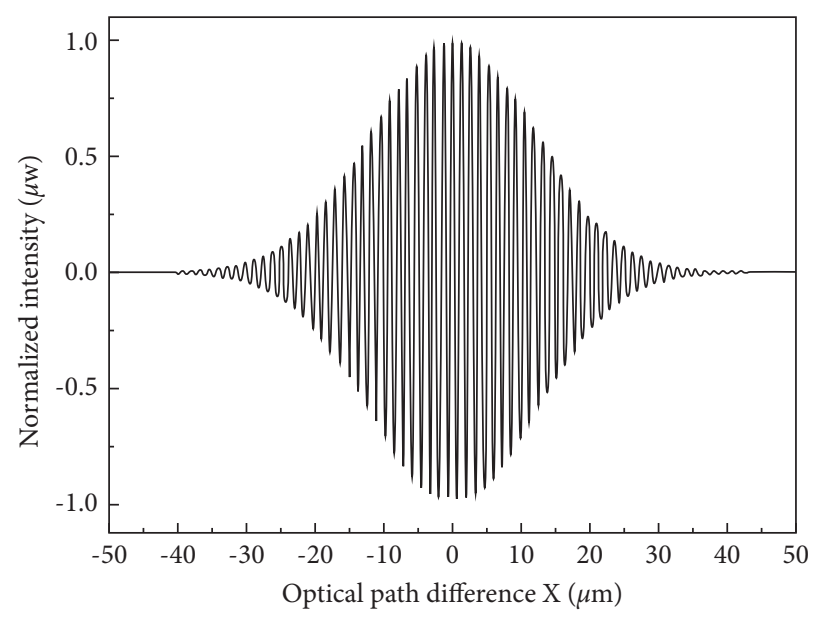

FIGURE 2: White light interference fringe.

The sensitivity of this sensing method depends on the length of the sensing fiber, and the longer the sensing fiber is, the more sensitive it is and the higher the resolution is [26]. However, the highest resolution of the system is limited by the resolution of the scanning mirror. This method is designed in an interferometer configuration, and its readout result is equivalent to the calibration by an optical grating. The optical grating of the instrument of WLI used in this study is a standard ruler with accuracy in two micrometers.

\section{Experimental Methodology}

3.1. Specimen Preparation. The concrete specimens were in the form of a cylinder with a diameter of $100 \mathrm{~mm}$ and a height of $150 \mathrm{~mm}$. River sand $(0-5 \mathrm{~mm})$ was regarded as the fine aggregate, and crushed limestone $(5-20 \mathrm{~mm})$ was used as coarse aggregate. The materials were mixed in a rotating drum laboratory mixer following ASTM C192-06 [27]. After 24 hours of casting, the cylinders were cured in such an environment, where the temperature is $20 \pm 3^{\circ} \mathrm{C}$, and relative humidity is $95 \%$ for 28 days. The mixed proportions of concrete and compressive strength on the $28^{\text {th }}$ day are given in Table 1.

After 28 days of curing, enwound a $7 \mathrm{~m}$ bare optical fiber in the middle of the cylinder with $1 \mathrm{~m}$ portions left at both ends; thus, the measuring optical fiber was $5 \mathrm{~m}$. The ends of the fiber were fixed with epoxy glue and protected with plastic casing as guided fiber. The enwound fiber was coated with epoxy, whose working temperature ranges from -60 
TABLE 1: Mix proportion of concrete and compressive strength.

\begin{tabular}{lccccc}
\hline W/C & Water $\left(\mathrm{kg} / \mathrm{m}^{3}\right)$ & Cement $\left(\mathrm{kg} / \mathrm{m}^{3}\right)$ & Fine aggregate $\left(\mathrm{kg} / \mathrm{m}^{3}\right)$ & Coarse aggregate $\left(\mathrm{kg} / \mathrm{m}^{3}\right)$ & Compressive strength $(\mathrm{MPa})$ \\
\hline 0.55 & 195 & 355 & 663 & 1178 & 43.2 \\
0.35 & 195 & 557 & 531 & 1128 & 55.2 \\
\hline
\end{tabular}

to $150{ }^{\circ} \mathrm{C}$. The thickness of the epoxy layer was about $1 \mathrm{~mm}$, and it provides physical protection for the enwinding fiber. The structural sketch and photo of the testing specimens are shown in Figure 3.

In order to eliminate the temperature effect on the strain measurement, temperature compensation specimens ( $\mathrm{T}$ specimen) were also fabricated. The concrete cylinders which were used to fabricate $\mathrm{T}$-specimens were dried in the oven in the condition of $40^{\circ} \mathrm{C}$ for four days, and then, it was necessary to repeat the fabricating process as mentioned above. After this process, seal it with plastic and put it into a rubber bucket to prevent it from absorbing moisture in the air during the experiment.

3.2. Construction of the F-T Monitoring System. The system comprises a sensing unit and a reference unit. The sensing unit is used to monitor the strain and the reference unit as the reference fiber and the data acquisition instrument. The monitoring system is shown in Figure 4. In the sensing unit, each specimen requires two couplers with split ratios of $90 \% /$ $10 \%$ and $50 \% / 50 \%$, which can be purchased in the markets. The coupler contains the output and input ports. The WLI instrument is connected with the input point of $10 \% / 90 \%$ coupler, and the two guided optical fibers are both linked to output ports. There are four specimens (two testing specimens and two T-specimens) in the sensing unit, which share the reference unit.

In the testing program, the sensing unit was placed in the concrete F-T tester, and it was immersed in the solution of $3.5 \% \mathrm{NaCl}$, as shown in Figure 5. The solution was poured into the rubber bucket, and the surface of the solution was $50 \mathrm{~mm}$ higher than the cylinder. The accelerated F-T testing program was conducted according to the standard for tent methods for rapid freezing and thawing [28]. Before starting the test, all the specimens were immersed for 4 days. The changes in temperature are shown in Figure 6. The $\mathrm{T}$-specimens were placed close to the testing specimens, and no solution was poured into the rubber bucket. During every 10 cycles, the strain was monitored by the WLI analytical instrument every 5 minutes, which was used to study the strain behavior during the F-T cycles.

\section{Experimental Results}

4.1. The Strain Behavior of T-Specimen. Optical fiber sensing technology is sensitive to temperature. Therefore, a reasonable temperature compensation method must be proposed. For this purpose, the strain behavior of the dry specimen (T-specimen) was measured and studied. The strain behavior of two different mixes T-specimens (dry specimen) for $10 \mathrm{~F}-\mathrm{T}$ cycles is shown in Figure 7.

As Figure 7 shows, the strain decreases with the decreasing temperature in the cooling stage and increases with the rising temperature in the heating stage. After one cycle, the level of strain returned to the initial state. The behavior of the strains shows good repeatability during the $10 \mathrm{~F}$-T cycles. This is because the T-specimens are dry, and the strain behaviors monitored by WLI are caused by the effect of linear expansion of the materials (concrete and optical fiber), which depends on the temperature change [29]. Therefore, eliminating the strain of T-specimen is a reasonable temperature compensation method in this test. It also can be seen that the range of strain of T- 0.55 (the T-specimen of W/ $\mathrm{C}=0.55$ ) is larger than that of $\mathrm{T}-0.35$ (the $\mathrm{T}$-specimen of $\mathrm{W} /$ $\mathrm{C}=0.35$ ), this is because $\mathrm{T}-0.55$ and $\mathrm{T}-0.35$ have different $\mathrm{W} /$ $C$ ratios, which have different coefficients of thermal expansion $[30,31]$.

4.2. The Method of Temperature Compensation. During the process of concrete material subjected to F-T cycles, the total strain $(\varepsilon)$ is composed of three components:

$$
\varepsilon=\varepsilon_{E}+\varepsilon_{T M}+\varepsilon_{T O} .
$$

In equation (3), $\varepsilon_{E}$ is the freezing expansion strain, which is caused by the volume expansion of water when it turns into ice. $\mathrm{E}_{T M}$ is the thermal expansion strain of the concrete material, which is caused by changes in temperature. $\mathrm{E}_{T O}$ is the strain of optical fiber caused by the temperature. In order to eliminate the strains $\varepsilon_{T M}$ and $\varepsilon_{T O}$, a dry concrete cylinder was fabricated as described in the preceding part of the text. The strain $\left(\varepsilon_{T \text {-specimen }}\right)$ which monitored from the T-specimen is the sum of $\varepsilon_{T M}$ and $\varepsilon_{T O}$. Therefore, the strain $\varepsilon_{E}$ is shown as the following equation:

$$
\varepsilon_{E}=\varepsilon-\varepsilon_{T-\text { specimen }}
$$

In this experiment, the total strain $\varepsilon$ is measured from the saturated specimen. The strain behavior for the two mixes before and after eliminating the $\varepsilon_{T \text {-specimen }}$ during the 10 cycles is shown in Figure 8 . After removing the strain $\varepsilon_{T-}$ specimen, strain $\varepsilon_{E}$ is increased in the cooing stage and decreased in the temperature rising stage. This phenomenon will be explained in the following part.

4.3. The Expansion Strain $\left(\varepsilon_{E}\right)$ Behavior during the F-T Cycles. In this test, the strain (freezing expansion strain $\varepsilon_{E}$ ) is monitored during every $10 \mathrm{~F}$-T cycles in real-time. There are no test data of the 71-80 cycles because the WLI instrument was broken down during the cycles.

Figure $9(\mathrm{a})(\mathrm{W} / \mathrm{C}=0.55)$ and Figure $9(\mathrm{~b})(\mathrm{W} / \mathrm{C}=0.35)$ show the behaviors of the strain from the start to the end during every $10 \mathrm{~F}-\mathrm{T}$ cycles. In the first $20 \mathrm{~F}-\mathrm{T}$ cycles, the residual strain has no obvious increase (early stage), as shown in Figure 9(a). This phenomenon is in the early stage of F-T cycles because the unfrozen water is transported into 


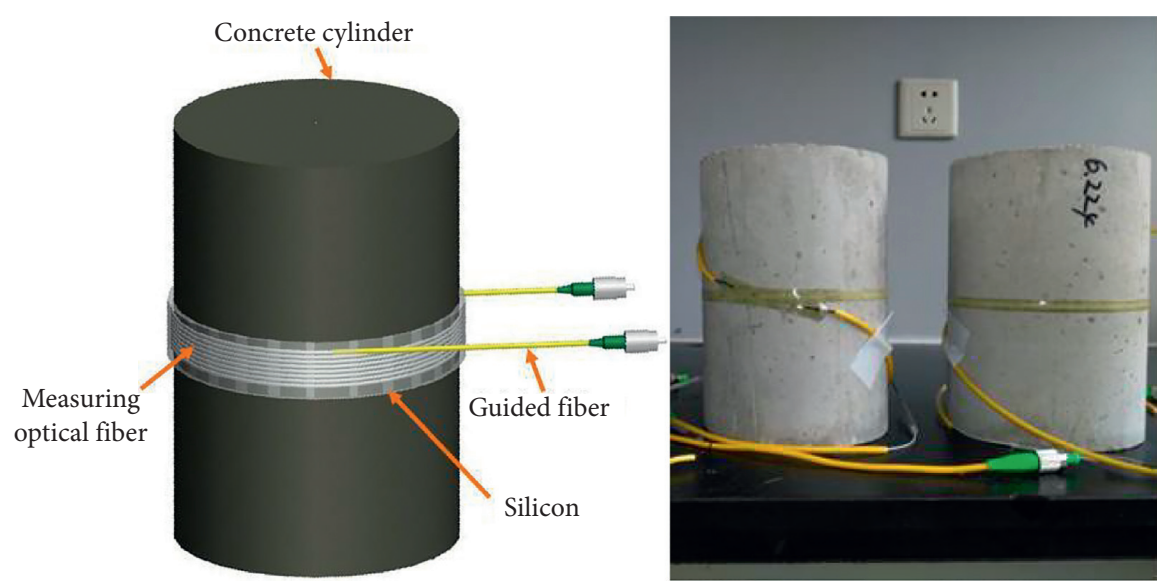

FIGURE 3: Structural sketch and photo of the testing specimens.

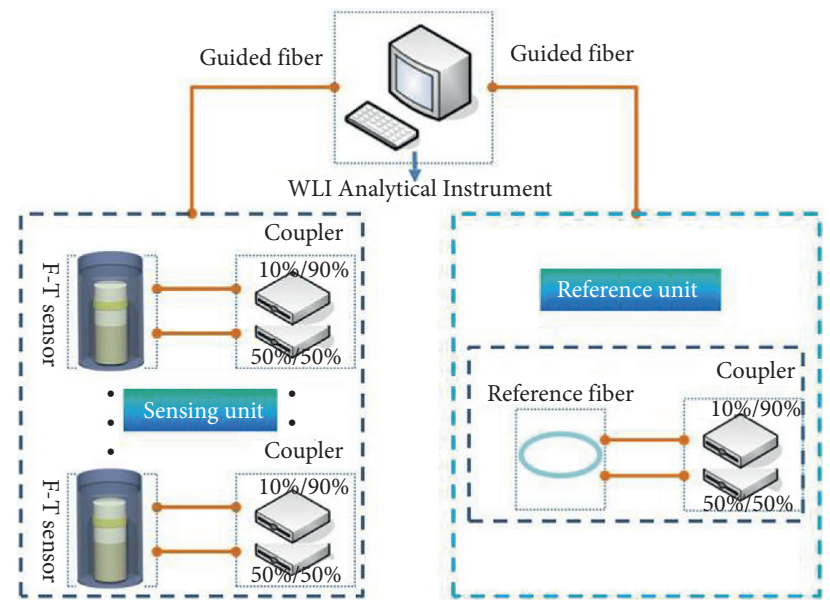

FIGURE 4: The diagram of the F-T monitoring system.

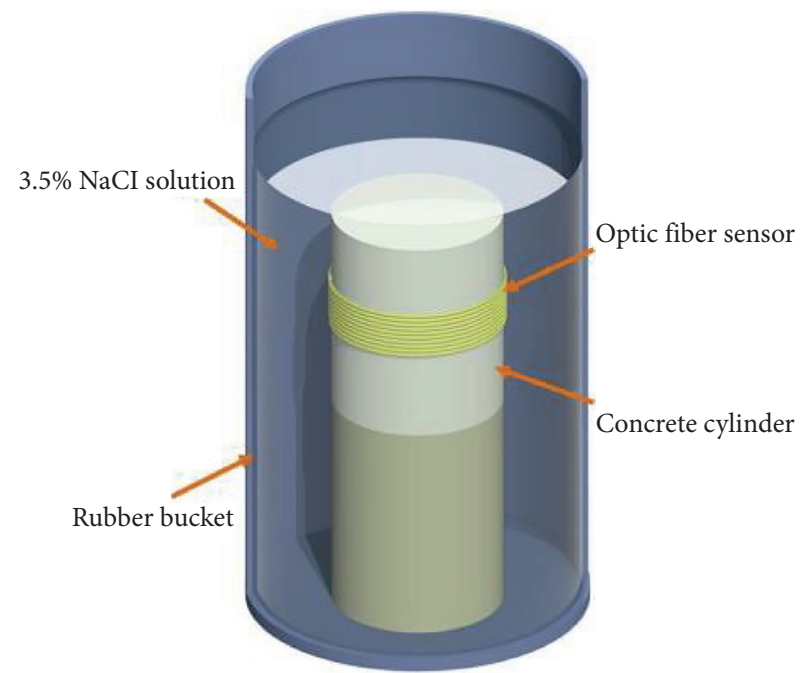

FIGURE 5: Schematic of the cylinder setting.

empty of partially filled pores by thermodynamic imbalance [28], and there are no microcracks or few microcracks produced in the matrix. After this period, residual strain increases with the F-T cycles, which means the damage was

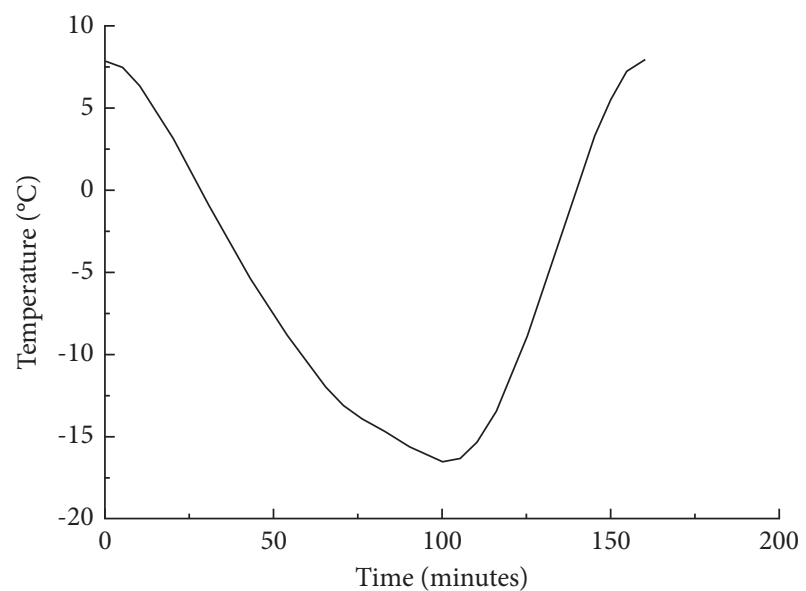

Figure 6: Accelerate F-T cycle.

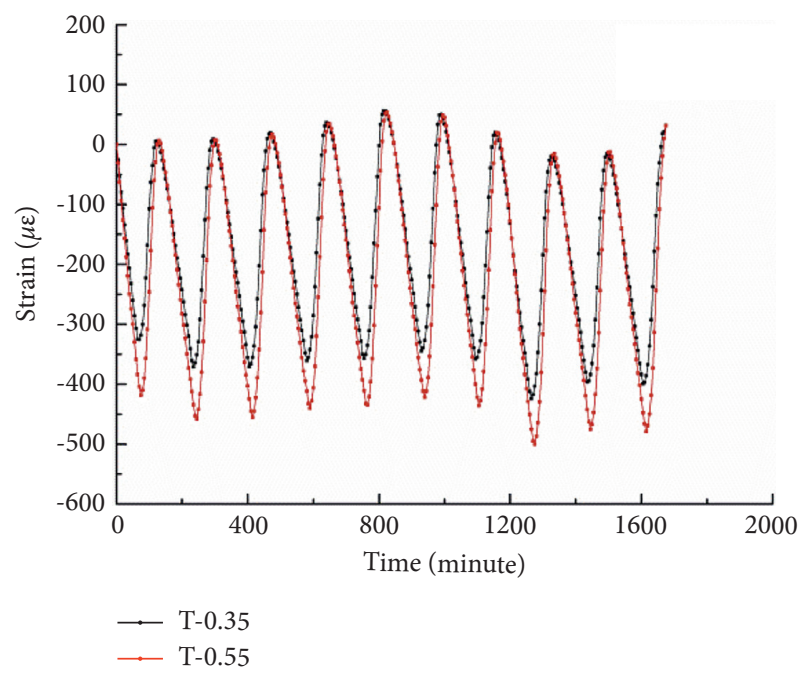

Figure 7: The strain behaviors of T-specimens.

induced in the matrix. The changing tendency of the residual shown in Figure 9(b) is similar to Figure 9(a). However, the early stage is more varied than that shown in Figure 9(a). This is because W/C 0.35 is lower than 0.55 . Concrete with 


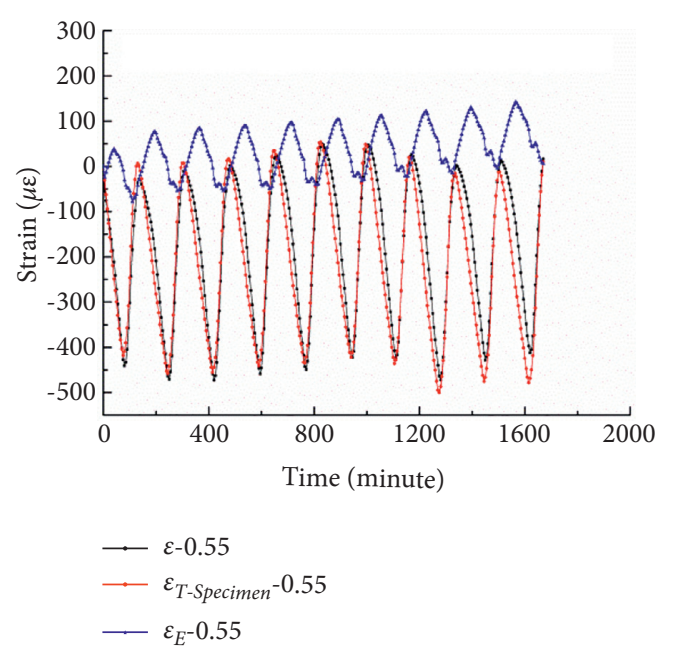

(a)

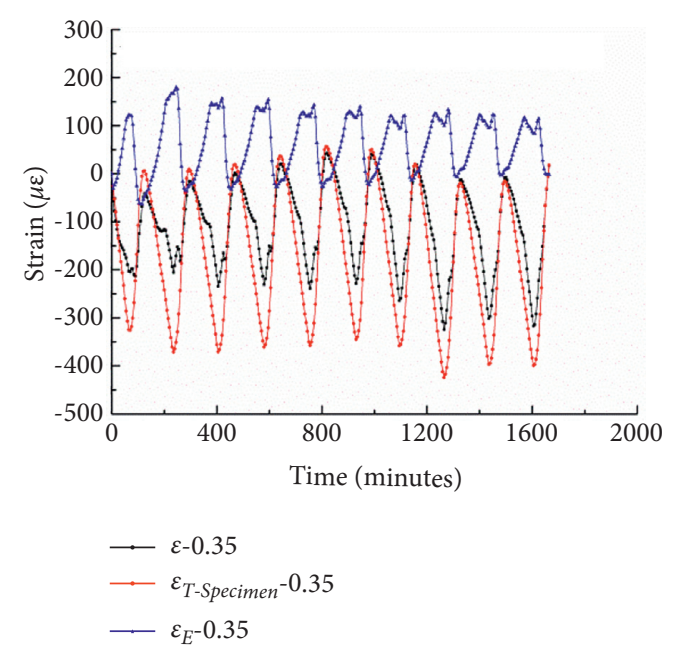

(b)

FIGURE 8: Strain behaviors before and after temperature compensation. (a) W/C $=0.55$. (b) $W / C=0.35$.

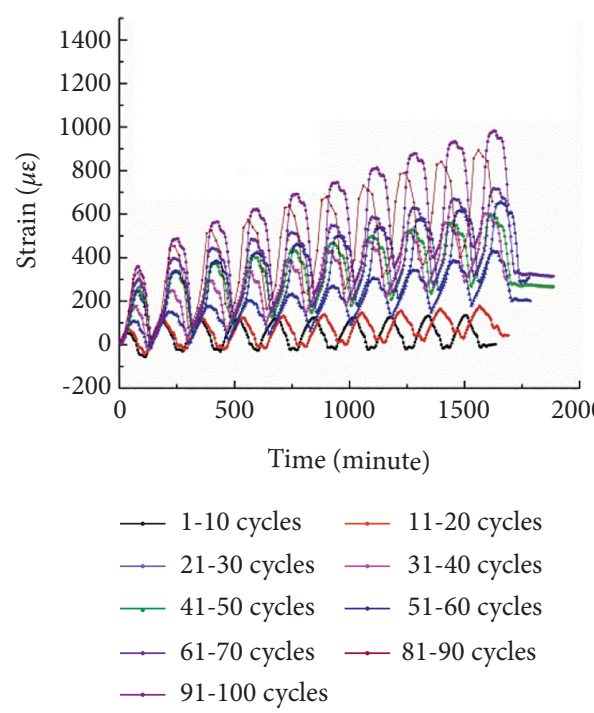

(a)

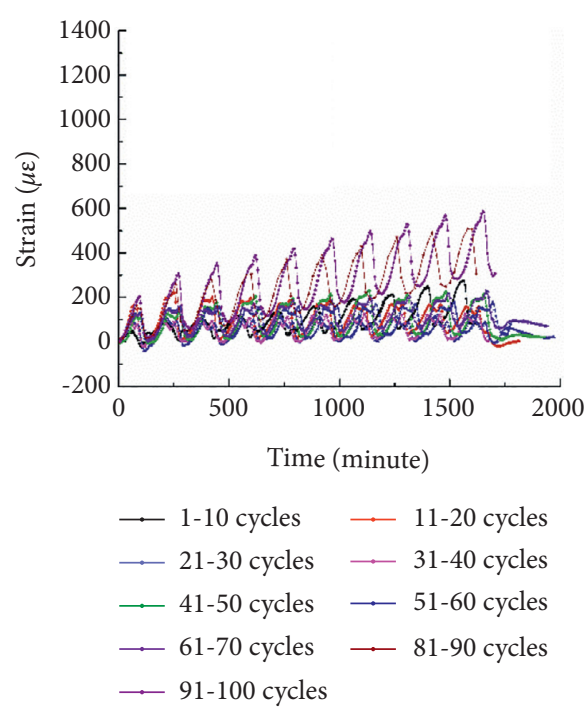

(b)

FIgURE 9: Strains from the start to the end during every $10 \mathrm{~F}-\mathrm{T}$ cycles. (a) W/C $=0.55$. (b) W/C $=0.35$.

lower $\mathrm{W} / \mathrm{C}$ has a more compact matrix. Therefore, the concrete matrix with different mixing ratios has different early stages when it is subjected to freeze-thaw. The lower W/ $\mathrm{C}$ is, the longer the early stage lasts, which can prolong the damage occurrence caused by F-T cycles.

In the whole process of the experiment, the behavior of residual strain shown in Figures 9(a) and 9(b) have the same tendency to change, which is the residual strain increased from the start to the end in every $10 \mathrm{~F}-\mathrm{T}$ cycles. As the number of F-T cycles increases, more water will be absorbed because of the existence of microcracks, which will induce more cracks in the matrix, resulting in a larger residual strain. Therefore, the growing trend of residual strain during every $10 \mathrm{~F}-\mathrm{T}$ cycles is increased with the F-T cycles, which demonstrates that the rate of damage in concrete increases with the F-T cycles.
In order to quantify the residual strain generated in the whole cycle, the behavior of stain from the start to the end of the whole test was calculated. At the beginning of the first F-T cycle, the strain was regarded as the initial strain. Thereafter, the strain was monitored during the F-T process subtracted the initial strain. Therefore, the residual strain at the end of any cycle is the accumulation of the previous cycles, as shown in Figures 10(a) and 10(b). After t100 F-T cycles, the residual strain of 0.55 specimen is $2880 \mu \varepsilon$, and the residual strain of 0.35 specimen is $1027 \mu \varepsilon$, which demonstrates that lower $\mathrm{W} / \mathrm{C}$ has higher resistance.

The residual strain increased with F-T cycles, which means that the damage evolution is accumulating cycle by cycle. In addition, the residual strain increases more significantly after certain cycles, which means more damages occur, such as the expansion of microcracks and increasing 


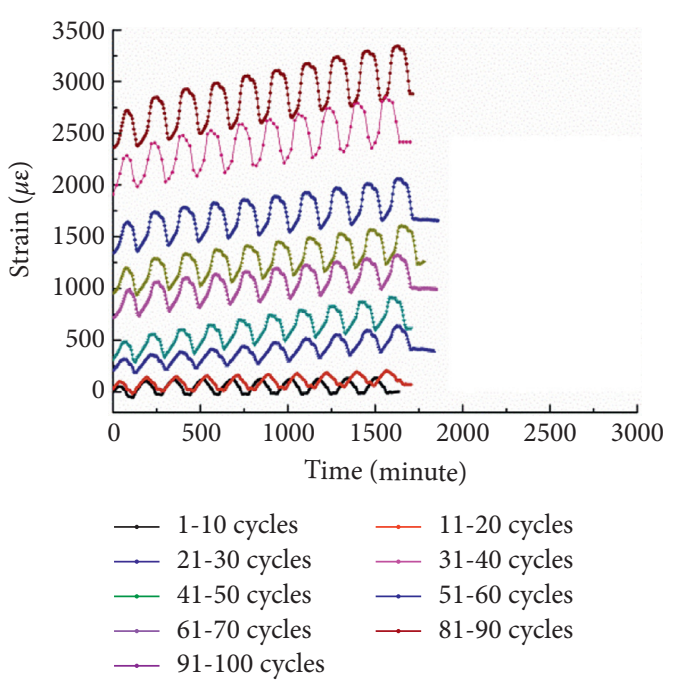

(a)

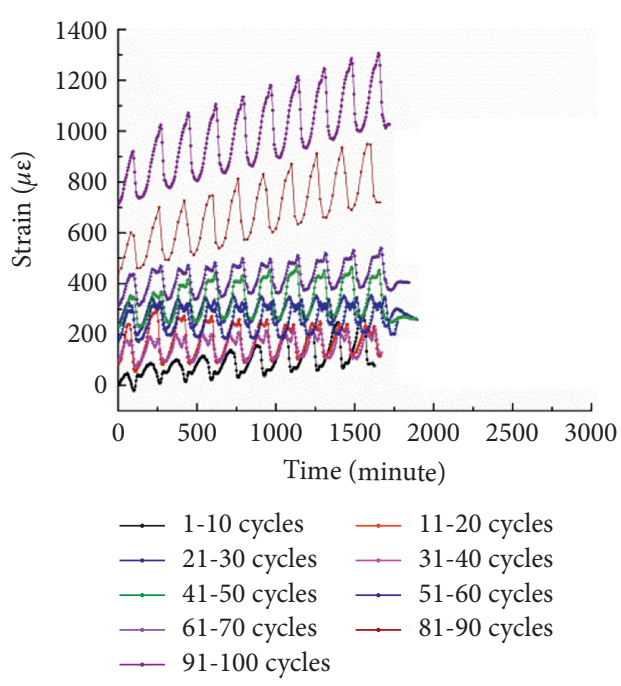

(b)

FIgURE 10: Strains from the start to the end of the whole F-T test. (a) W/C $=0.55$. (b) W/C $=0.35$.

the diameter of the capillary. According to the value of residual strain, the inner degeneration of the concrete matrix caused by F-T cycles can be quantified.

\section{Conclusions}

In this study, the strain behavior of concrete subjected to F-T cycles was monitored in real-time and studied. Based on the WLI technique, a fiber optic F-T testing method was proposed, designed, and tested. The results demonstrate that strain will be induced when the concrete cylinder is subjected to F-T cycles, and the method can monitor the changing behavior of strain in real-time. Residual strain is induced subjected to F-T cycles.

When cylinders are subjected to the same F-T cycles, the strain of $\mathrm{W} / \mathrm{C}=0.35$ is lower than $\mathrm{W} / \mathrm{C}=0.55$, which demonstrates that reducing the $\mathrm{W} / \mathrm{C}$ ratio can reduce the development of strain. In addition, a lower $\mathrm{W} / \mathrm{C}$ ratio has a longer early stage, which prolongs the microcracks produced in the matrix. The residual strain is increased with F-Tcycles, which means that the damage evolution involved damage accumulated gradually cycle by cycle, indicating it can quantify the inner damage after certain $\mathrm{F}-\mathrm{T}$ cycles from the perspective of residual strain.

\section{Data Availability}

The data used to support the findings of this study are obtained by experimental measurements.

\section{Conflicts of Interest}

The authors declare that they have no conflicts of interest.

\section{Acknowledgments}

This study was financially supported by the Natural Science Foundation of Shandong Province, China (ZR2020QE254).

\section{References}

[1] B. Wang, F. Wang, and Q. Wang, "Damage constitutive models of concrete under the coupling action of freeze-thaw cycles and load based on Lemaitre assumption," Construction and Building Materials, vol. 173, pp. 332-341, 2018.

[2] S. Bishnoi and T. Uomoto, "Strain-temperature hysteresis in concrete under cyclic freeze-thaw conditions," Cement and Concrete Composites, vol. 30, no. 5, pp. 374-380, 2008.

[3] Z. Song, H. Konietzky, and X. Cai, "Modulus degradation of concrete exposed to compressive fatigue loading: insights from lab testing," Structural Engineering \& Mechanics, vol. 78, no. 3, pp. 281-296, 2021.

[4] ASTM C666/C666M-03, Standard Test Method for Resistance of concrete to Rapid Freezing and Thawing, American Society for Testing Materials, West Conshohocken, PA, USA, 2003.

[5] L. Tang and P.-E. Petersson, "Slab test: freeze/thaw resistance of concrete-Internal deterioration," Materials and Structures, vol. 37, no. 10, pp. 754-759, 2004.

[6] B. Johannesson, "Dimensional and ice content changes of hardened concrete at different freezing and thawing temperatures," Cement and Concrete Composites, vol. 32, no. 1, pp. 73-83, 2010.

[7] H. Marzouk and D. Jiang, "Effects of freezing and thawing on the tension properties of high-strength concrete," ACI Materials Journal, vol. 91, no. 6, pp. 577-586, 1994.

[8] J. H. Rutherford, B. W. Langan, and M. A. Ward, "Use of control specimens in freezing and thawing testing of concrete," CemConcrAggreg, vol. 16, no. 1, pp. 78-82, 1994.

[9] Z. D. Wang, Q. Zeng, L. Wang, K. F. Li, S. L. Xu, and Y. Yao, "Characterizing frost damages of concrete with flatbed scanner," Construction and Building Materials, vol. 102, pp. 872-883, 2016.

[10] S. Li, G. Chen, G. Ji, and Y. Lu, "Quantitative damage evaluation of concrete suffered freezing-thawing by DIP technique," Construction and Building Materials, vol. 69, pp. 177-185, 2014.

[11] T. Suzuki, H. Ogata, R. Takada, M. Aoki, and M. Ohtsu, "Use of acoustic emission and X-ray computed tomography for damage evaluation of freeze-thawed concrete," Construction and Building Materials, vol. 24, pp. 2347-2352, 2010. 
[12] Z. Zhou, X. Cai, X. Li, W. Cao, and X. Du, "Dynamic response and energy evolution of sandstone under coupled static-dynamic compression: insights from experimental study into deep rock engineering applications," Rock Mechanics and Rock Engineering, vol. 53, no. 3, pp. 1305-1331, 2020.

[13] M. Molero, S. Aparicio, G. Al-Assadi, M. J. Casati, M. G. Hernández, and J. J. Anaya, "Evaluation of freeze-thaw damage in concrete by ultrasonic imaging," NDT \& E International, vol. 52, pp. 86-94, 2012.

[14] X. Cai, Z. Zhou, L. Tan, H. Zang, and Z. Song, "Fracture behavior and damage mechanisms of sandstone subjected to wetting-drying cycles," Engineering Fracture Mechanics, vol. 234, Article ID 107109, 2020.

[15] H. Jia, S. Ding, F. Zi, Y. Dong, and Y. Shen, "Evolution in sandstone pore structures with freeze-thaw cycling and interpretation of damage mechanisms in saturated porous rocks," Catena, vol. 195, 2020.

[16] H. Jia, D. Shun, Z. Fan, G. Li, and Y. Yao, "Development of anisotropy in sandstone subjected to repeated frost action," Rock Mechanics and Rock Engineering, vol. 54, no. 3, p. 3, 2021.

[17] M. J. Setzer, P. Heine, S. Kasparek et al., "Test methods of frost resistance of concrete: CIF-Test: c," Materials and Structures, vol. 37, no. 10 , pp. 743-753, 2004

[18] Q. Meng, M. Zhang, L. Han, H. Pu, and T. Nie, "Effects of acoustic emission and energy evolution of rock specimens under the uniaxial cyclic loading and unloading compression," Rock Mechanics and Rock Engineering, vol. 49, no. 10, pp. 1-14, 2016.

[19] Z. Song, Y. Wang, H. Konietzky, and X. Cai, "Mechanical behavior of marble exposed to freeze-thaw-fatigue loading," International Journal of Rock Mechanics and Mining Sciences, vol. 138, Article ID 104648, 2021.

[20] J. Ranz, S. Aparicio, H. Romero, M. Casati, M. Molero, and M. González, "Monitoring of freeze-thaw cycles in concrete using embedded sensors and ultrasonic imaging," Sensors, vol. 14, no. 2, pp. 2280-2304, 2014.

[21] J. Cao and D. D. L. Chung, "Damage evolution during freezethaw cycling of cement mortar, studied by electrical resistivity measurement," Cement and Concrete Research, vol. 32, no. 10, pp. 1657-1661, 2002.

[22] S. Bishnoi, Strain Variations in concrete Subjected to Cyclic Freezing and Thawing, MS Thesis, University of Tokyo, Tokyo, Japan, 2004.

[23] Y. Wang, B. Zhang, B. Li, and C. Li, "A strain-based fatigue damage model for naturally fractured marble subjected to freeze-thaw and uniaxial cyclic loads," International Journal of Damage Mechanics, vol. 30, no. 6, 2021.

[24] Z. Song, T. Frühwirt, and H. Konietzky, "Inhomogeneous mechanical behaviour of concrete subjected to monotonic and cyclic loading," International Journal of Fatigue, vol. 132, Article ID 105383, 2020.

[25] X. Zhao, Y. Cui, H. Wei, X. Kong, P. Zhang, and C. Sun, "Research on corrosion detection for steel reinforced concrete structures using the fiber optical white light interferometer sensing technique," Smart Materials and Structures, vol. 22, no. 6, Article ID 065014, 2013.

[26] L. Yuan, "Optical path automatic compensation low-coherence interferometric fibre-optic temperature sensor," Optics \& Laser Technology, vol. 30, no. 1, pp. 33-38, 1998.

[27] Aashto R 39-2019, Standard Practice for Making and Curing Concrete Test Specimens in the Laboratory, 2019.
[28] Gb/T. 50082-2009, Standard for Test Methods of Long-Term Performance and Durability of Ordinary concrete, China architecture and building press, Beijing, China, 2009.

[29] H. Lv, K. Liao, X. Kong, X. Zhao, and C. Sun, "Monitoring the residual strain of concrete in a freezing-thawing environment using white light interferometer," Cold Regions Science and Technology, vol. 142, pp. 132-138, 2017.

[30] Z. D. Wang, Y. Yao, and L. Wang, "Research on the apparent thermal expansion coefficient of concrete subject to freezethaw cycles and chloride salt a," Advanced Materials Research, vol. 446-449, pp. 3304-3310, 2012.

[31] E. Sicat, F. Gong, D. Zhang, and T. Ueda, "Change of the coefficient of thermal expansion of mortar due to damage by freeze thaw cycles," Journal of Advanced Concrete Technology, vol. 11, no. 12, pp. 333-346, 2013. 